\title{
Soil-Pile Interaction in the Pile Vertical Vibration Based on Fictitious Soil-Pile Model
}

\author{
Guodong Deng, ${ }^{1}$ Jiasheng Zhang, ${ }^{1}$ Wenbing Wu, ${ }^{2}$ Xiong Shi, ${ }^{1}$ and Fei Meng ${ }^{1}$ \\ ${ }^{1}$ School of Civil Engineering, Central South University, Changsha, Hunan 410075, China \\ ${ }^{2}$ Engineering Faculty, China University of Geosciences, Wuhan, Hubei 430074, China \\ Correspondence should be addressed to Jiasheng Zhang; zjsznu@163.com and Wenbing Wu; zjuwwb1126@163.com
}

Received 15 November 2013; Revised 9 April 2014; Accepted 12 April 2014; Published 15 May 2014

Academic Editor: Hui-Shen Shen

Copyright (C) 2014 Guodong Deng et al. This is an open access article distributed under the Creative Commons Attribution License, which permits unrestricted use, distribution, and reproduction in any medium, provided the original work is properly cited.

By introducing the fictitious soil-pile model, the soil-pile interaction in the pile vertical vibration is investigated. Firstly, assuming the surrounding soil of pile to be viscoelastic material and considering its vertical wave effect, the governing equations of soilpile system subjected to arbitrary harmonic dynamic force are founded based on the Euler-Bernoulli rod theory. Secondly, the analytical solution of velocity response in frequency domain and its corresponding semianalytical solution of velocity response in time domain are derived by means of Laplace transform technique and separation of variables technique. Based on the obtained solutions, the influence of parameters of pile end soil on the dynamic response is studied in detail for different designing parameters of pile. Lastly, the fictitious soil-pile model and other pile end soil supporting models are compared. It is shown that the dynamic response obtained by the fictitious soil-pile model is among the dynamic responses obtained by other existing models if there are appropriate material parameters and thickness of pile end soil for the fictitious soil-pile model.

\section{Introduction}

The soil-pile dynamic interaction is a complicated and multifaceted contact problem. During vibration, the pile not only interacts with the surrounding soil of pile, but also interacts with the pile end soil. Thus, the soil-pile dynamic interaction has been widely studied and many kinds of dynamic interaction models on this topic have been presented in the existing literatures. From the viewpoint of surrounding soilpile dynamic interaction, the existing models can be classified into three categories, that is, dynamic Winkler model [16], Plane-Strain model [7-11], and various three-dimensional axisymmetric continuum models [12-16]. It can be seen that extensive and in-depth research work has been done in the field of surrounding soil-pile dynamic interaction.

However, for the pile end soil-pile dynamic interaction, the existing research findings on this topic are not sufficient due to the difficulty to build rigorous coupling model for the dynamic interaction of pile end soil and pile. In general, there are two basic approaches to deal with this contact problem. In the first approach, the dynamic support condition of pile end soil on the pile is assumed to be rigid boundary $[3,10,16]$. This simplified method can be used in the condition that the pile is end bearing, but it is not sufficiently accurate for most floating piles. The other approach is that the support condition of pile end soil is supposed to be elastic boundary (modeled by a linear spring) $[2,11,14,15]$ or viscoelastic boundary (modeled by a linear spring and a dashpot connected in parallel) $[1,5,6]$. Although these methods are amenable to practical application in pile nondestructive testing, the parameters of spring and dashpot cannot be gained by means of routine soil tests. There are also many kinds of empirical methods to obtain the two parameters, for instance, simulating formula method [17], constant value method [1], $Q-z$ curve equation method [18], ultimate bearing capacity method [19], and so on. However, all the aforementioned methods cannot take into account the frequency of load. In order to overcome the above shortcomings, Yang and Wang [20] and Wu et al. [21] presented a simplified model to simulate the dynamic interaction between the pile end soil and pile, namely, fictitious soil-pile model. Soon afterwards, Wu et al. [22] verified the accuracy of this model by comparing it with the model test results. The parameters of fictitious soilpile model are closely related to the parameters of pile end 


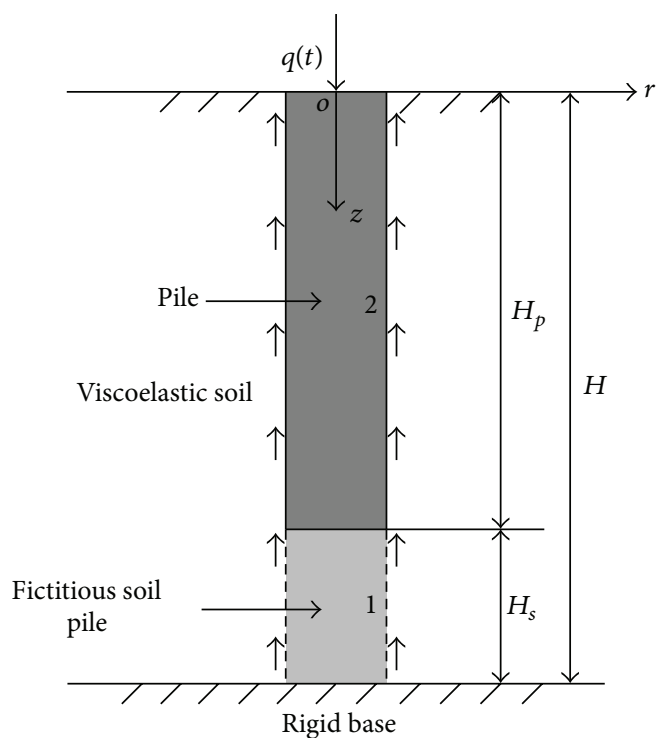

FIGURE 1: Schematic of pile-soil interaction model.

soil. Meanwhile, this model can take into consideration the layered characteristics and construction effect of pile end soil. Therefore, the fictitious soil-pile model is an effective model.

In light of this, in order to extend the application of the fictitious soil-pile model, this paper has introduced it to study the vertical dynamic response of pile embedded in viscoelastic soil. Then, the analytical solution of velocity response in frequency domain and its corresponding semianalytical solution of velocity response in time domain are derived. Based on these solutions, the influence of parameters of pile end soil on the pile dynamic response is investigated.

\section{Mathematical Model and Assumptions}

2.1. Computational Model. The problem studied here is the vertical vibration of pile embedded in viscoelastic soil considering its vertical wave effect. The diagram of soil-pile interaction model is shown in Figure $1 . H_{p}$ and $r_{0}$ represent the length and radius of pile, respectively. $q(t)$ is the arbitrary harmonic force acting on the pile head. The thickness of foundation soil and pile end soil is denoted by $H$ and $H_{s}$, respectively. Based on the fictitious soil-pile model, the soilpile system can be divided into two parts, that is, the pile end soil-pile system and the surrounding soil-pile system, which are numbered by 1 and 2, respectively. follows.

The main assumptions adopted in this paper are as

(1) The soil is a homogeneous, isotropic, and viscoelastic layer. The damping force of soil is proportional to the strain rate, and the coefficient of proportionality is denoted by $\eta_{s}$.

(2) The top surface of soil layer is assumed to be free boundary with no normal and shear stresses, and the bottom surface of soil layer is assumed to be rigid boundary.
(3) The soil-pile system is subjected to small deformations and strains during vibration.

(4) The pile and fictitious soil pile are perfectly elastic and vertical with a uniform circular cross-section and have perfect contact with the surrounding soil during vibration.

2.2. Governing Equations of Soil-Pile System. The axisymmetric problem of vertical harmonic oscillations in linearly elastic soil is taken into account in this paper. Denoting $w=$ $w(r, z, t)$ to be the vertical displacement of soil, the dynamic equilibrium equation of soil motion allowing for its vertical wave effect can be expressed as

$$
\begin{aligned}
& \left(\lambda_{s}+2 G_{s}\right) \frac{\partial^{2} w}{\partial z^{2}}+G_{s}\left(\frac{1}{r} \frac{\partial w}{\partial r}+\frac{\partial^{2} w}{\partial r^{2}}\right)+\eta_{s} \frac{\partial}{\partial t}\left(\frac{\partial^{2} w}{\partial z^{2}}\right) \\
& +\eta_{s} \frac{\partial}{\partial t}\left(\frac{1}{r} \frac{\partial w}{\partial r}+\frac{\partial^{2} w}{\partial r^{2}}\right)=\rho_{s} \frac{\partial^{2} w}{\partial t^{2}},
\end{aligned}
$$

where $\lambda_{s}$ and $G_{s}$ represent the Lame constants of soil which should satisfy $\lambda_{s}=E_{s} \mu_{s} /\left[\left(1+\mu_{s}\right)\left(1-2 \mu_{s}\right)\right]$ and $G_{s}=\rho_{s} V_{s}^{2}$. $E_{s}, \mu_{s}, V_{s}$, and $\rho_{s}$ denote the elastic modulus, Poisson's ratio, shear wave velocity, and density of soil, respectively.

Based on the viscoelasticity theory, the shear stress at any point in the soil layer can be expressed as

$$
\tau_{s, r z}=G_{s} \frac{\partial w}{\partial r}+\eta_{s} \frac{\partial^{2} w}{\partial t \partial r} .
$$

Denoting $u_{j}=u_{j}(z, t)$ to be the vertical displacement of pile (including fictitious soil pile) and according to the EulerBernoulli rod theory, the dynamic equilibrium equation of pile can be written as

$$
\begin{array}{r}
E_{p, j} A_{p, j} \frac{\partial^{2} u_{j}}{\partial z^{2}}-m_{p, j} \frac{\partial^{2} u_{j}}{\partial t^{2}}-2 \pi r_{0} \tau_{s, r z}\left(r_{0}, z, t\right)=0 \\
(j=1,2),
\end{array}
$$

where $E_{p, j}, A_{p, j}$, and $m_{p, j}$ represent the elastic modulus, cross-sectional area, and mass per unit length of pile (including fictitious soil pile), respectively. When $j=1$ and $j=2$, these above parameters refer to the parameters of fictitious soil pile and pile, respectively.

Combining with the assumptions, the boundary and initial conditions of soil-pile system can be established as follows.

(1) Boundary conditions of soil are as follows. At the top surface of soil,

$$
\left.\frac{\partial w}{\partial z}\right|_{z=0}=0
$$

At the bottom surface of soil,

$$
\left.w\right|_{z=H}=0 .
$$

At an infinite radial distance of soil,

$$
\sigma(\infty, z)=0, \quad w(\infty, z)=0 .
$$


(2) Boundary conditions of pile are as follows:

$$
\begin{gathered}
\left.\frac{\partial u_{2}}{\partial z}\right|_{z=0}=-\frac{q(t)}{E_{p, 2} A_{p, 2}}, \\
\left.u_{1}\right|_{z=H}=0 \\
\left.u_{1}\right|_{z=H_{p}}=\left.u_{2}\right|_{z=H_{p}}, \\
\left.E_{p, 1} A_{p, 1} \frac{\partial u_{1}}{\partial z}\right|_{z=H_{p}}=\left.E_{p, 2} A_{p, 2} \frac{\partial u_{2}}{\partial z}\right|_{z=H_{p}} .
\end{gathered}
$$

(3) At the interface of soil-pile system,

$$
w\left(r_{0}, z, t\right)=u_{j}(z, t), \quad(j=1,2) .
$$

(4) Initial conditions of soil-pile system are as follows. Initial conditions of soil are

$$
\left.w\right|_{t=0}=0,\left.\quad \frac{\partial w}{\partial t}\right|_{t=0}=0,\left.\quad \frac{\partial^{2} w}{\partial t^{2}}\right|_{t=0}=0 .
$$

Initial conditions of pile are

$$
\left.u_{j}\right|_{t=0}=0,\left.\quad \frac{\partial u_{j}}{\partial t}\right|_{t=0}=0
$$

\section{Solutions of the Equations}

3.1. Vibrations of the Soil Layer. Denote $W(r, z, s)$ to be the Laplace transform with respect to time of $w(r, z, t)$. Associating with the initial conditions (7a), (1) is transformed by using the Laplace transform technique and can be further written as

$$
\begin{aligned}
& \left(\lambda_{s}+2 G_{s}+\eta_{s} \cdot s\right) \frac{1}{Z(z)} \frac{\partial^{2} Z(z)}{\partial z^{2}} \\
& +\left(G_{s}+\eta_{s} \cdot s\right) \frac{1}{R(r)}\left(\frac{1}{r} \frac{\partial R(r)}{\partial r}+\frac{\partial^{2} R(r)}{\partial r^{2}}\right)=\rho_{s} s^{2},
\end{aligned}
$$

where $W(r, z, s)=\int_{0}^{+\infty} w(r, z, t) e^{-s t} \mathrm{~d} t . s$ is the Laplace transform parameter which should satisfy $s=i \omega$ during the numerical analysis.

By means of the separation of variables technique, (8) can be decoupled as follows:

$$
\begin{gathered}
\frac{\mathrm{d}^{2} R(r)}{\mathrm{d} r^{2}}+\frac{1}{r} \frac{\mathrm{d} R(r)}{\mathrm{d} r}-\xi^{2} R(r)=0, \\
\frac{\mathrm{d}^{2} Z(z)}{\mathrm{d} z^{2}}+\beta^{2} Z(z)=0,
\end{gathered}
$$

where constants $\beta$ and $\xi$ must satisfy the following relationship:

$$
\xi^{2}=\frac{\left(\lambda_{s}+2 G_{s}+\eta_{s} \cdot s\right) \beta^{2}+\rho_{s} s^{2}}{G_{s}+\eta_{s} \cdot s}
$$

Equation (9) represents the Bessel equation and ordinary differential equation of second order whose general solutions can be easily obtained. Associating with these general solutions, the vertical displacement of soil, $W(r, z, s)$, can be derived as

$$
\begin{aligned}
W(r, z, s)= & {\left[A K_{0}(\xi r)+B I_{0}(\xi r)\right] } \\
& \times[C \sin (\beta z)+D \cos (\beta z)],
\end{aligned}
$$

where $I_{0}(\cdot)$ and $K_{0}(\cdot)$ represent the modified Bessel functions of order zero of the first and second kinds, respectively. $A, B, C$, and $D$ are constants determined by the boundary conditions.

According to the properties of the modified Bessel functions, that is, if $r \rightarrow \infty$, then $I_{n}(\cdot) \rightarrow \infty$ and $K_{n}(\cdot) \rightarrow 0$, it can be obtained that $B=0$ and $C=0$ from boundary conditions (4c) and (4a). By virtue of boundary condition (4b), the following equation can be obtained:

$$
\cos (\beta H)=0 .
$$

By solving (12), it can be obtained that $\beta_{n}=(\pi / 2 H)(2 n-$ 1) $(n=1,2,3, \ldots)$. Substituting this formula into (11), $W(r, z, s)$ can be rewritten as

$$
W(r, z, s)=\sum_{n=1}^{\infty} A_{n} K_{0}\left(\xi_{n} r\right) \cos \left(\beta_{n} z\right)
$$

where $A_{n}$ are a series of constants which can be obtained from the boundary conditions. $\xi_{n}$ can be obtained by substituting $\beta=\beta_{n}$ into (10).

3.2. Vibrations of the Pile. Denoting $U(z, s)$ to be the Laplace transform with respect to time of $u(z, t),(3)$ is transformed by using the Laplace transform technique and can be rewritten combining (2) and (13):

$$
\begin{aligned}
& V_{p, j}^{2} \frac{\partial^{2} U_{j}}{\partial z^{2}}-s^{2} U_{j}-\frac{2 \pi r_{0}}{\rho_{p, j} A_{p, j}}\left(G_{s}+\eta_{s} \cdot s\right) \\
& \quad \times \sum_{n=1}^{\infty} A_{n} \xi_{n} K_{1}\left(\xi_{n} r_{0}\right) \cos \left(\beta_{n} z\right)=0, \quad(j=1,2),
\end{aligned}
$$

where $V_{p, j}=\sqrt{E_{p, j} / \rho_{p, j}}$ represents the elastic longitudinal wave velocity of pile (including fictitious soil pile). Letting $\lambda^{2}=-s^{2}$, the general solution of (14) can be derived as

$$
U_{j}=M_{j} \cos \left(\frac{\lambda}{V_{p, j}} z\right)+N_{j} \sin \left(\frac{\lambda}{V_{p, j}} z\right)+\sum_{n=1}^{\infty} \phi_{j n} \cos \left(\beta_{n} z\right),
$$

where $\phi_{j n}=-2 \pi r_{0}\left(G_{s}+\eta_{s} \cdot s\right) A_{n} \xi_{n} K_{1}\left(\xi_{n} r_{0}\right) / \rho_{p, j} A_{p, j}\left[\left(\beta_{n} V_{p, j}\right)^{2}\right.$ $+s^{2}$ ] and $K_{1}(\cdot)$ represents the modified Bessel function of order one of the second kind.

Based on the fictitious soil-pile model, the impedance function at the head of fictitious soil pile can be obtained. Then, substituting the impedance function into the governing 
equation of pile, the solution of pile dynamic response can be obtained. Therefore, the governing equation of pile can be solved through two steps.

Step I (deriving the displacement impedance function at the head of fictitious soil pile). Taking the Laplace transform of (6) and substituting the vertical displacements of fictitious soil pile and its surrounding soil into (6), the following equation can be obtained by means of orthogonality of the inherent function system $\cos \left(\beta_{n} z\right)$ in the interval $\left[0, H_{s}\right]$ :

$$
\begin{gathered}
\frac{M_{1}}{2}\left[\frac{\sin \left[\left(\left(\lambda / V_{p, 1}\right)+\beta_{n}\right) H_{s}\right]}{\left(\lambda / V_{p, 1}\right)+\beta_{n}}+\frac{\sin \left[\left(\left(\lambda / V_{p, 1}\right)-\beta_{n}\right) H_{s}\right]}{\left(\lambda / V_{p, 1}\right)-\beta_{n}}\right] \\
-\frac{N_{1}}{2}\left[\frac{\cos \left[\left(\left(\lambda / V_{p, 1}\right)+\beta_{n}\right) H_{s}\right]-1}{\left(\lambda / V_{p, 1}\right)+\beta_{n}}\right. \\
\left.+\frac{\cos \left[\left(\left(\lambda / V_{p, 1}\right)-\beta_{n}\right) H_{s}\right]-1}{\left(\lambda / V_{p, 1}\right)-\beta_{n}}\right] \\
=A_{n}\left[K_{0}\left(\xi_{n} r_{0}\right)+\frac{2 \pi r_{0}\left(G_{s}+\eta_{s} \cdot s\right) \xi_{n} K_{1}\left(\xi_{n} r_{0}\right)}{\rho_{p, 1} A_{p, 1}\left[\left(\beta_{n} V_{p, 1}\right)^{2}+s^{2}\right]}\right] \\
\times \int_{0}^{H_{s}} \cos ^{2}\left(\beta_{n} z\right) \mathrm{d} z .
\end{gathered}
$$

Substituting (16) into (15), the vertical displacement at the head of fictitious soil pile can be derived as

$$
\begin{aligned}
U_{1}= & M_{1}\left[\cos \left(\frac{\lambda}{V_{p, 1}} z\right)+\sum_{n=1}^{\infty} \chi_{1 n}^{\prime} \cos \left(\beta_{n} z\right)\right] \\
& +N_{1}\left[\sin \left(\frac{\lambda}{V_{p, 1}} z\right)-\sum_{n=1}^{\infty} \chi_{1 n}^{\prime \prime} \cos \left(\beta_{n} z\right)\right],
\end{aligned}
$$

where

$$
\begin{array}{r}
\chi_{1 n}^{\prime}=\chi_{1 n}\left[\frac{\sin \left[\left(\left(\lambda / V_{p, 1}\right)+\beta_{n}\right) H_{s}\right]}{\left(\lambda / V_{p, 1}\right)+\beta_{n}}\right. \\
\left.+\frac{\sin \left[\left(\left(\lambda / V_{p, 1}\right)-\beta_{n}\right) H_{s}\right]}{\left(\lambda / V_{p, 1}\right)-\beta_{n}}\right], \\
\chi_{1 n}^{\prime \prime}=\chi_{1 n}\left[\frac{\cos \left[\left(\left(\lambda / V_{p, 1}\right)+\beta_{n}\right) H_{s}\right]-1}{\left(\lambda / V_{p, 1}\right)+\beta_{n}}\right. \\
\left.+\frac{\cos \left[\left(\left(\lambda / V_{p, 1}\right)-\beta_{n}\right) H_{s}\right]-1}{\left(\lambda / V_{p, 1}\right)-\beta_{n}}\right],
\end{array}
$$

$$
\begin{aligned}
\chi_{1 n} & =-\frac{\pi r_{0}\left(G_{s}+\eta_{s} \cdot s\right) \xi_{n} K_{1}\left(\xi_{n} r_{0}\right)}{\rho_{p, 1} A_{p, 1}\left[\left(\beta_{n} V_{p, 1}\right)^{2}+s^{2}\right] \varphi_{1 n} L_{1 n}}, \\
L_{1 n} & =\int_{0}^{H_{s}} \cos ^{2}\left(\beta_{n} z\right) \mathrm{d} z .
\end{aligned}
$$

Taking the Laplace transform of boundary condition (5c) and substituting (17) into boundary condition (5c), the following equation can be obtained:

$$
\frac{M_{1}}{N_{1}}=-\frac{\sin \left(\left(\lambda / V_{p, 1}\right) H\right)-\sum_{n=1}^{\infty} \chi_{1 n}^{\prime \prime} \cos \left(\beta_{n} H\right)}{\cos \left(\left(\lambda / V_{p, 1}\right) H\right)+\sum_{n=1}^{\infty} \chi_{1 n}^{\prime} \cos \left(\beta_{n} H\right)} .
$$

Then, the displacement impedance function at the head of fictitious soil pile can be derived as

$$
\begin{aligned}
Z_{1}(s)= & \frac{-\left.E_{p, 1} A_{p, 1}\left(\partial U_{1} / \partial z\right)\right|_{z^{\prime}=0}}{\left.U_{1}\right|_{z^{\prime}=0}} \\
= & -E_{p, 1} A_{p, 1} \\
& \times\left(\left(-\frac{M_{1}}{N_{1}}\left[\frac{\lambda}{V_{p, 1}} \sin \left(\frac{\lambda}{V_{p, 1}} H_{p}\right)\right.\right.\right. \\
& \left.+\sum_{n=1}^{\infty} \chi_{1 n}^{\prime} \beta_{n} \sin \left(\beta_{n} H_{p}\right)\right] \\
& +\left[\frac{\lambda}{V_{p, 1}} \cos \left(\frac{\lambda}{V_{p, 1}} H_{p}\right)\right. \\
& \left.\left.+\sum_{n=1}^{\infty} \chi_{1 n}^{\prime \prime} \beta_{n} \sin \left(\beta_{n} H_{p}\right)\right]\right) \\
& \times\left(\frac { M _ { 1 } } { N _ { 1 } } \left[\cos \left(\frac{\lambda}{V_{p, 1}} H_{p}\right)\right.\right. \\
& +\left[\frac{\lambda}{V_{p, 1}} H_{p}\right) \\
& \left.\left.\left.-\sum_{n=1}^{\infty} \chi_{1 n}^{\prime \prime} \cos \left(\beta_{n} H_{p}\right)\right]\right)^{-1}\right) .
\end{aligned}
$$

Step II (deriving the displacement impedance function at the head of pile). In the same solving manner of (16), the following equation can be obtained:

$$
\begin{aligned}
& \frac{M_{2}}{2}\left[\frac{\sin \left[\left(\left(\lambda / V_{p, 2}\right)+\beta_{n}\right) H_{p}\right]}{\left(\lambda / V_{p, 2}\right)+\beta_{n}}\right. \\
&\left.+\frac{\sin \left[\left(\left(\lambda / V_{p, 2}\right)-\beta_{n}\right) H_{p}\right]}{\left(\lambda / V_{p, 2}\right)-\beta_{n}}\right]
\end{aligned}
$$




$$
\begin{gathered}
-\frac{N_{2}}{2}\left[\frac{\cos \left[\left(\left(\lambda / V_{p, 2}\right)+\beta_{n}\right) H_{p}\right]-1}{\left(\lambda / V_{p, 2}\right)+\beta_{n}}\right. \\
\left.+\frac{\cos \left[\left(\left(\lambda / V_{p, 2}\right)-\beta_{n}\right) H_{p}\right]-1}{\left(\lambda / V_{p, 2}\right)-\beta_{n}}\right] \\
=A_{n}\left[K_{0}\left(\xi_{n} r_{0}\right)+\frac{2 \pi r_{0}\left(G_{s}+\eta_{s} \cdot s\right) \xi_{n} K_{1}\left(\xi_{n} r_{0}\right)}{\rho_{p, 2} A_{p, 2}\left[\left(\beta_{n} V_{p, 2}\right)^{2}+s^{2}\right]}\right] \\
\times \int_{0}^{H_{p}} \cos ^{2}\left(\beta_{n} z\right) \mathrm{d} z .
\end{gathered}
$$

Substituting (21) into (15), the vertical displacement at the head of pile can be derived as

$$
\begin{aligned}
U_{2}= & M_{2}\left[\cos \left(\frac{\lambda}{V_{p, 2}} z\right)+\sum_{n=1}^{\infty} \chi_{2 n}^{\prime} \cos \left(\beta_{n} z\right)\right] \\
& +N_{2}\left[\sin \left(\frac{\lambda}{V_{p, 2}} z\right)-\sum_{n=1}^{\infty} \chi_{2 n}^{\prime \prime} \cos \left(\beta_{n} z\right)\right],
\end{aligned}
$$

where

$$
\begin{gathered}
\chi_{2 n}^{\prime}=\chi_{2 n}\left[\frac{\sin \left[\left(\left(\lambda / V_{p, 2}\right)+\beta_{n}\right) H_{p}\right]}{\left(\lambda / V_{p, 2}\right)+\beta_{n}}\right. \\
\left.+\frac{\sin \left[\left(\left(\lambda / V_{p, 2}\right)-\beta_{n}\right) H_{p}\right]}{\left(\lambda / V_{p, 2}\right)-\beta_{n}}\right], \\
\chi_{2 n}^{\prime \prime}=\chi_{2 n}\left[\frac{\cos \left[\left(\left(\lambda / V_{p, 2}\right)+\beta_{n}\right) H_{p}\right]-1}{\left(\lambda / V_{p, 2}\right)+\beta_{n}}\right. \\
\left.+\frac{\cos \left[\left(\left(\lambda / V_{p, 2}\right)-\beta_{n}\right) H_{p}\right]-1}{\left(\lambda / V_{p, 2}\right)-\beta_{n}}\right], \\
\chi_{2 n}=-\frac{\pi r_{0}\left(G_{s}+\eta_{s} \cdot s\right) \xi_{n} K_{1}\left(\xi_{n} r_{0}\right)}{\rho_{p, 2} A_{p, 2}\left[\left(\beta_{n} V_{p, 2}\right)^{2}+s^{2}\right] \varphi_{2 n} L_{2 n}}, \\
\varphi_{2 n}=K_{0}\left(\xi_{n} r_{0}\right)+\frac{2 \pi r_{0}\left(G_{s}+\eta_{s} \cdot s\right) \xi_{n} K_{1}\left(\xi_{n} r_{0}\right)}{\rho_{p, 2} A_{p, 2}\left[\left(\beta_{n} V_{p, 2}\right)^{2}+s^{2}\right]}, \\
L_{2 n}=\int_{0}^{H_{p}} \cos ^{2}\left(\beta_{n} z\right) \mathrm{d} z .
\end{gathered}
$$

Substituting (20) into the governing equation of pile and combining the boundary conditions (5c) and (5d), the following equation can be derived:

$$
\begin{aligned}
& \frac{M_{2}}{N_{2}} \\
& \quad=\left(\left[\frac{\lambda}{V_{p, 2}} \cos \left(\frac{\lambda}{V_{p, 2}} H_{p}\right)+\sum_{n=1}^{\infty} \chi_{2 n}^{\prime \prime} \beta_{n} \sin \left(\beta_{n} H_{p}\right)\right]\right.
\end{aligned}
$$

$$
\begin{gathered}
\left.+\frac{Z_{1}(s)}{E_{p, 2} A_{p, 2}}\left[\sin \left(\frac{\lambda}{V_{p, 2}} H_{p}\right)-\sum_{n=1}^{\infty} \chi_{2 n}^{\prime \prime} \cos \left(\beta_{n} H_{p}\right)\right]\right) \\
\times\left(\left[\frac{\lambda}{V_{p, 2}} \sin \left(\frac{\lambda}{V_{p, 2}} H_{p}\right)+\sum_{n=1}^{\infty} \chi_{2 n}^{\prime} \beta_{n} \sin \left(\beta_{n} H_{p}\right)\right]\right. \\
-\frac{Z_{1}(s)}{E_{p, 2} A_{p, 2}}\left[\cos \left(\frac{\lambda}{V_{p, 2}} H_{p}\right)\right. \\
\left.\left.+\sum_{n=1}^{\infty} \chi_{2 n}^{\prime} \cos \left(\beta_{n} H_{p}\right)\right]\right)^{-1} .
\end{gathered}
$$

Then, the displacement impedance function at the head of pile can be derived as

$$
\begin{aligned}
Z_{2}(s) & =\frac{-\left.E_{p, 2} A_{p, 2}\left(\partial U_{2} / \partial z\right)\right|_{z=0}}{\left.U_{2}\right|_{z=0}} \\
& =-\frac{E_{p, 2} A_{p, 2}}{H_{p}} \frac{\bar{\lambda}}{\left(M_{2} / N_{2}\right)\left(1+\sum_{n=1}^{\infty} \chi_{2 n}^{\prime}\right)-\sum_{n=1}^{\infty} \chi_{2 n}^{\prime \prime}},
\end{aligned}
$$

where $\bar{\lambda}=\lambda T_{c}$ is dimensionless quantity. $T_{c}=H_{p} / V_{p, 2}$ represents the propagation time of elastic longitudinal wave propagating from the pile head to pile end.

The velocity transit function at the head of pile can be derived as

$$
\begin{aligned}
G_{v}(s) & =\frac{s}{Z_{2}(s)} \\
& =-\frac{s H_{p}}{E_{p, 2} A_{p, 2} \bar{\lambda}}\left[\frac{M_{2}}{N_{2}}\left(1+\sum_{n=1}^{\infty} \chi_{2 n}^{\prime}\right)-\sum_{n=1}^{\infty} \chi_{2 n}^{\prime \prime}\right] .
\end{aligned}
$$

Letting $s=i \omega$ and substituting it into (26) yield the velocity response at pile head in frequency domain:

$$
H_{v}(i \omega)=\frac{i \omega}{Z_{2}(i \omega)}=-\frac{1}{\rho_{p, 2} A_{p, 2} V_{p, 2}}\left|H_{v}^{\prime}\right|,
$$

where $\left|H_{v}^{\prime}\right|$ is the dimensionless velocity admittance at pile head which can be expressed as

$$
\left|H_{v}^{\prime}\right|=\left|i\left[\frac{M_{2}}{N_{2}}\left(1+\sum_{n=1}^{\infty} \chi_{2 n}^{\prime}\right)-\sum_{n=1}^{\infty} \chi_{2 n}^{\prime \prime}\right]\right| .
$$

By means of the inverse Fourier transform, the velocity response in time domain at pile head can be obtained as $V(t)=\operatorname{IFT}\left[Q(\omega) H_{v}(i \omega)\right]$, where $Q(\omega)$ denotes the Fourier transform of $q(t)$, which is the vertical excitation acting on the pile head.

In particular, the excitation can be regarded as a half-sine pulse in the nondestructive detection of pile foundation as follows:

$$
q(t)= \begin{cases}Q_{\max } \sin \left(\frac{\pi}{T} t\right), & t \in(0, T), \\ 0, & t \geq T,\end{cases}
$$


where $T$ and $Q_{\max }$ denote the duration of the impulse or impulse width and the maximum amplitude of the vertical excitation, respectively. Then, the velocity response in time domain of the pile head can be expressed as

$$
\begin{aligned}
V(t) & =\operatorname{IFT}\left[Q(i \omega) \cdot H_{v}(i \omega)\right] \\
& =-\frac{Q_{\max }}{\rho_{p, 2} A_{p, 2} V_{p, 2}} V_{v}^{\prime}
\end{aligned}
$$

where $V_{v}^{\prime}$ is the dimensionless velocity response which can be expressed as

$$
\begin{array}{r}
V_{v}^{\prime}=\frac{1}{2} \int_{-\infty}^{\infty} i\left[\frac{M_{2}}{N_{2}}\left(1+\sum_{n=1}^{\infty} \chi_{2 n}^{\prime}\right)-\sum_{n=1}^{\infty} \chi_{2 n}^{\prime \prime}\right] \\
\times \frac{\bar{T}}{\pi^{2}-\bar{T}^{2} \bar{\omega}^{2}} \cdot\left(1+e^{-i \bar{\omega} \bar{T}}\right) e^{i \bar{\omega} \bar{t}} \mathrm{~d} \bar{\omega}
\end{array}
$$

where $\bar{\omega}=T_{c} \omega$ represents the dimensionless frequency. $\bar{T}$ represents the dimensionless pulse width which should satisfy $\bar{T}=T / T_{c} \cdot \bar{t}$ represents the dimensional time variable which should satisfy $\bar{t}=t / T_{c}$.

\section{Analysis of Vibration Characteristics}

Based on the solutions, a parametric study is conducted to investigate the influence of thickness of pile end soil on the dynamic response at pile head. Unless otherwise specified, parameters of homogeneous foundation used here are given as follows: the density, shear wave velocity, Poisson's ratio and viscous damping coefficient of soil are $1800 \mathrm{~kg} / \mathrm{m}^{3}, 180 \mathrm{~m} / \mathrm{s}$, 0.4 and $1000 \mathrm{~N} \cdot \mathrm{m}^{-3} \cdot \mathrm{s}$, respectively.

4.1. Influence of Thickness of Pile End Soil on the Dynamic Response at Pile Head for Different Pile Lengths. Pile length is an important parameter in the design of pile bearing capacity, and the existing researches have shown that pile length also has significant influence on the dynamic response of pile. Therefore, it is needed to discuss the influence of thickness of pile end soil on the dynamic response at pile head for different pile lengths. Parameters used here are as follows. The pile lengths are $10 \mathrm{~m}$ and $20 \mathrm{~m}$, respectively. The radius, density, and elastic longitudinal wave velocity of pile are $0.5 \mathrm{~m}, 2500 \mathrm{~kg} / \mathrm{m}^{3}$, and $3800 \mathrm{~m} / \mathrm{s}$, respectively. Denoting $d$ to be the diameter of pile, then the thickness of pile end soil is $H_{s}=0.5 d, 1 d, 3 d, 5 d, 10 d$, respectively.

Figures 2 and 3 show the influence of thickness of pile end soil on the dynamic response at pile head for different pile lengths. As shown in Figures 2(a) and 3(a), it can be seen that the velocity admittance curves oscillate about the mean amplitude as the frequency increases and the shorter the pile is, the more remarkable the change regulation is. It can also be noted that the velocity admittance curves tend to be convergent as the thickness of pile end soil increases. If the thickness of pile end soil is beyond a certain value, say, $H_{s}=5 d$ in this case, the further increase of thickness of pile end soil no longer affects the velocity admittance, which means that there is a critical influence thickness of pile end soil. As shown in Figures 2(b) and 3(b), the pile head will receive the reverse reflected signal back from the bedrock when the pile end soil is thin enough, and the shorter the pile is, the stronger the reflected wave signal is. It can be noted that the reflected wave signal curves also tend to be convergent as the thickness of pile end soil increases. If the thickness of pile end soil is beyond a certain value, the further increase of thickness of pile end soil has little influence on the reflected wave signal curves.

The above results show that when the thickness is beyond this critical influence thickness, further increase of the thickness of the pile end soil has little influence on the dynamic response of pile. Nevertheless, when the thickness of the pile end soil is less than this critical influence thickness, it has significant influence on the dynamic response of pile.

\subsection{Influence of Thickness of Pile End Soil on the Dynamic} Response at Pile Head for Different Pile Radii. In this section, the influence of thickness of pile end soil on the dynamic response at pile head for different pile radii is studied. Parameters used here are as follows. The pile radii are $0.3 \mathrm{~m}$ and $0.5 \mathrm{~m}$, respectively. The length, density, and elastic longitudinal wave velocity of pile are $15 \mathrm{~m}, 2500 \mathrm{~kg} / \mathrm{m}^{3}$, and $3800 \mathrm{~m} / \mathrm{s}$, respectively. The thickness of pile end soil is $H_{s}=$ $0.5 d, 1 d, 3 d, 5 d, 10 d$, respectively.

Figures 4 and 5 show the influence of thickness of pile end soil on the dynamic response at pile head for different pile radii. As shown in Figures 4(a) and 5(a), the amplitude of resonance peaks gradually decreases as the thickness of pile end soil increases, but the resonance frequency of velocity admittance curves basically remains unchanged. It can also be seen that the velocity admittance curves tend to be convergent if the thickness of pile end soil is beyond the critical influence thickness. As shown in Figures 4(b) and 5(b), the reflected wave signal curves also tend to be convergent as the thickness of pile end soil increases. Figures 4 and 5 also show that the larger the pile radius is, the more remarkable the above change regulation is.

4.3. Influence of Thickness of Pile End Soil on the Dynamic Response at Pile Head for Different Elastic Longitudinal Wave Velocities of Pile. In this section, the influence of thickness of pile end soil on the dynamic response at pile head for different elastic longitudinal wave velocities of pile is studied. Parameters used here are as follows. The elastic longitudinal wave velocities of pile are $3600 \mathrm{~m} / \mathrm{s}$ and $4000 \mathrm{~m} / \mathrm{s}$, respectively. The length, radius, and density of pile are $15 \mathrm{~m}, 0.5 \mathrm{~m}$, and $2500 \mathrm{~kg} / \mathrm{m}^{3}$, respectively. The thickness of pile end soil is $H_{s}=0.5 d, 1 d, 3 d, 5 d, 10 d$, respectively.

Figures 6 and 7 show the influence of thickness of pile end soil on the dynamic response at pile head for different elastic longitudinal wave velocities of pile. As shown in Figures 6(a) and $7(a)$, with the increase of thickness of pile end soil, the resonance frequency of velocity admittance curves basically remains unchanged, but the amplitude of resonance peaks gradually decreases. It can also be noted that the velocity admittance curves tend to be convergent if the thickness of 


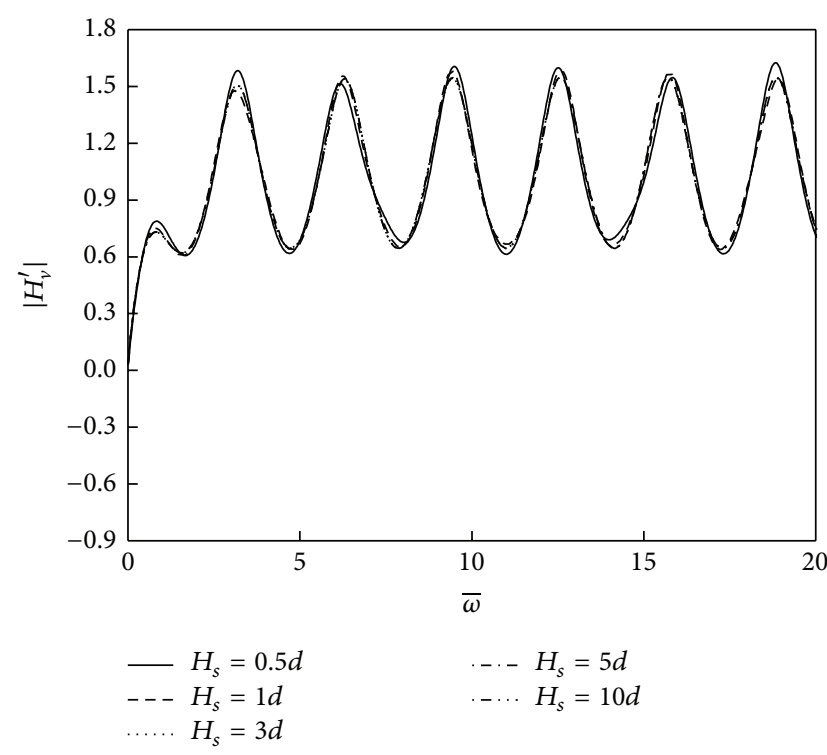

(a) Velocity admittance curves

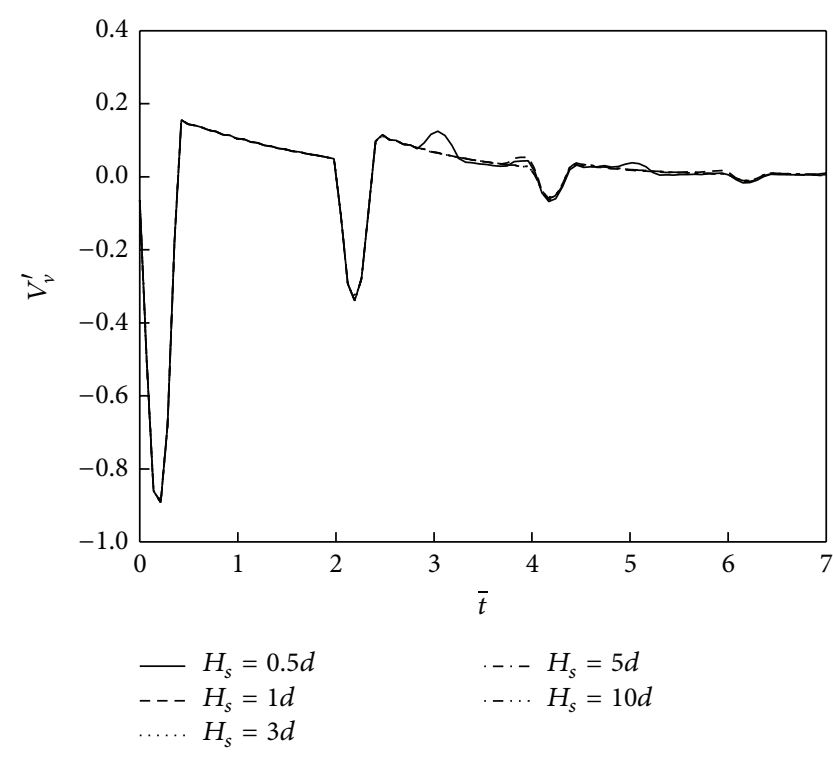

(b) Reflected wave signal curves

FIGURE 2: Influence of thickness of pile end soil on the dynamic response at pile head when $H_{p}=10 \mathrm{~m}$.

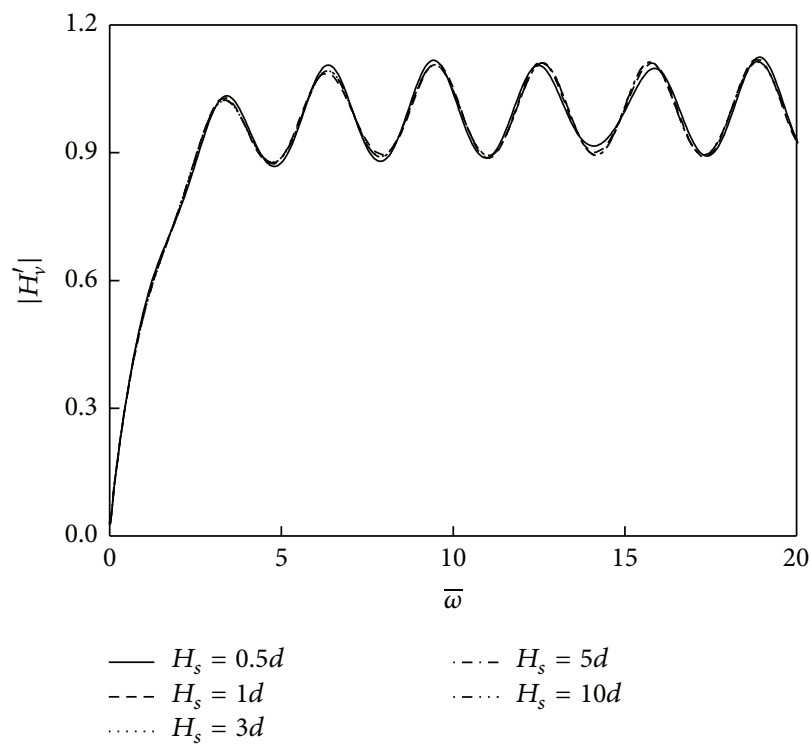

(a) Velocity admittance curves

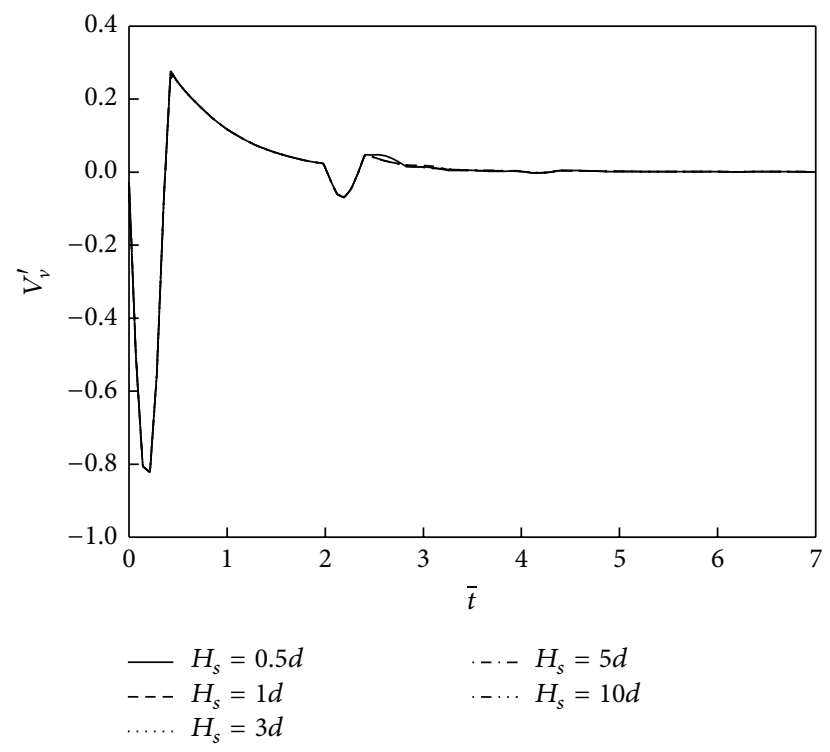

(b) Reflected wave signal curves

FIGURE 3: Influence of thickness of pile end soil on the dynamic response at pile head when $H_{p}=20 \mathrm{~m}$.

pile end soil is beyond the critical influence thickness. As shown in Figures 6(b) and 7(b), it can be noted that the reflected wave signal curves also tend to be convergent as the thickness of pile end soil increases. Figures 6 and 7 also show that the larger the elastic longitudinal wave velocity of pile is, the more remarkable the above change regulation is.

\section{Comparison with Other Models}

In this section, the fictitious soil-pile model is compared with other models mentioned in the introduction. No matter the support condition of pile end is rigid or viscoelastic, it can be described by the complex impedance of pile end which can be expressed as

$$
Z_{b}=k_{b}+\eta_{b} \cdot i \omega
$$

where $k_{b}$ and $\eta_{b}$ represent the spring constant and damping coefficient of the support condition of pile end. Then, the various support condition of pile end can be reflected by adjusting these two parameters. Parameters used here are the length, radius, density, and elastic longitudinal wave velocity of pile which are $15 \mathrm{~m}, 0.5 \mathrm{~m}, 2500 \mathrm{~kg} / \mathrm{m}^{3}$, and $3800 \mathrm{~m} / \mathrm{s}$, 


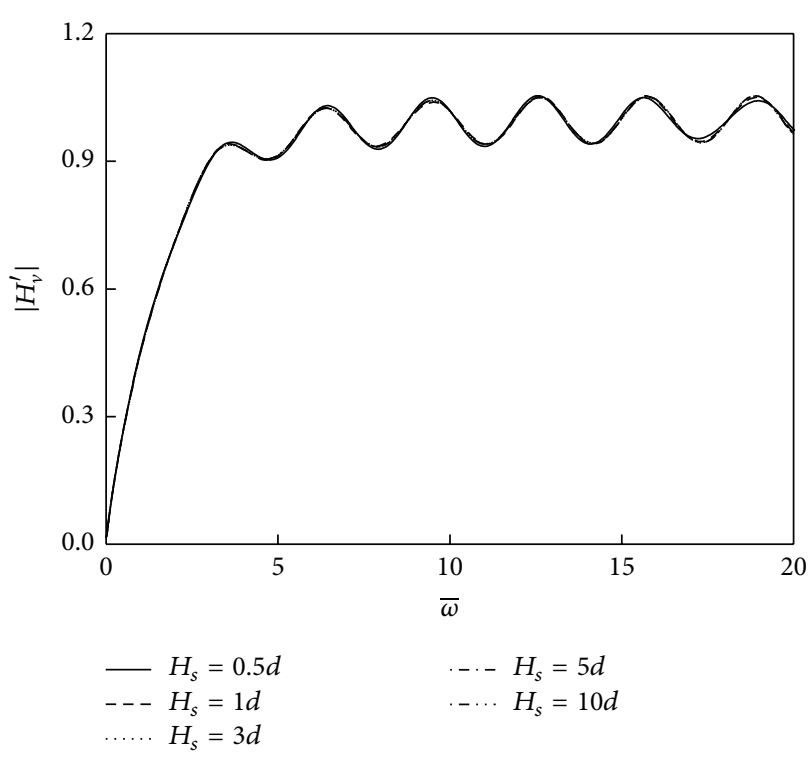

(a) Velocity admittance curves

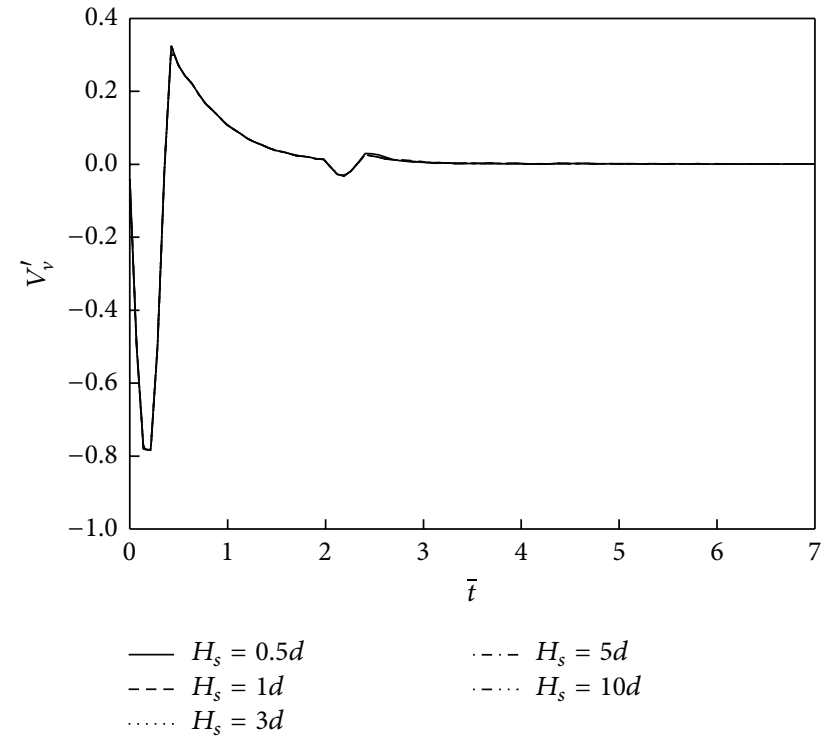

(b) Reflected wave signal curves

FIGURE 4: Influence of thickness of pile end soil on the dynamic response at pile head when $r_{0}=0.3 \mathrm{~m}$.

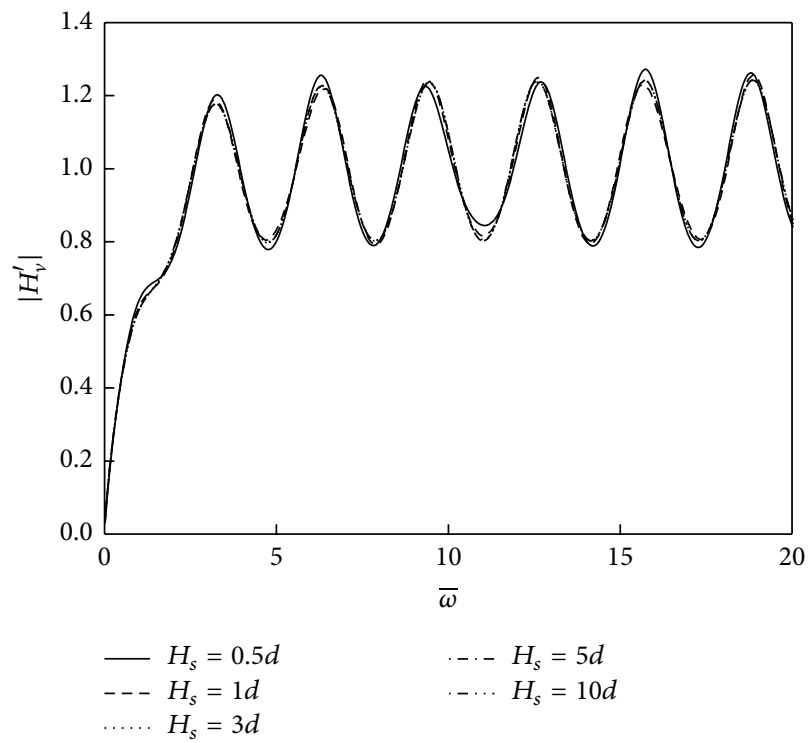

(a) Velocity admittance curves

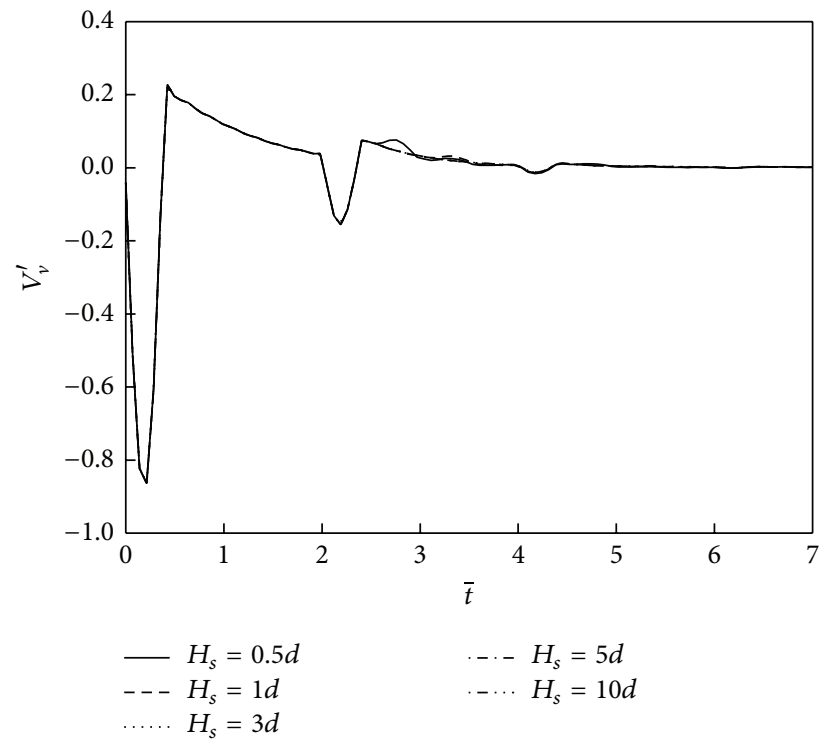

(b) Reflected wave signal curves

FIGURE 5: Influence of thickness of pile end soil on the dynamic response at pile head when $r_{0}=0.5 \mathrm{~m}$.

respectively. The thickness of pile end soil is $2 d$. The support condition of pile end can be regarded to be free if $k_{b}=0$, $\eta_{b}=0$ and rigid if $k_{b}=\infty, \eta_{b}=\infty$ and viscoelastic otherwise.

Figure 8 presents the comparison of the fictitious soil-pile model with other models. As shown in Figure 8(a), it can be noted that the case of free support is out of phase opposite to the case of rigid support; that is, the phase angle difference of these two cases is close to $180^{\circ}$. The phase angle difference varies from $0^{\circ}$ to $180^{\circ}$ when the values of $k_{b}$ and $\eta_{b}$ are other constants. It can also be noted that the amplitude of resonance peaks gradually decreases firstly and then gradually increases when the values of $k_{b}$ and $\eta_{b}$ vary from zero to infinity. As shown in Figure 8(b), it can be noted that the amplitude of reflected wave signals at pile end gradually decreases firstly and then increases when the values of $k_{b}$ and $\eta_{b}$ vary from zero to infinite. The reflected wave signal is orthokinetic when the complex impedance of pile end is small; for example, $k_{b}=$ $0, \eta_{b}=0$ and $k_{b}=0.1, \eta_{b}=0.06$. Meanwhile, the reflected wave signal is reverse when the complex impedance of pile end is large; for example, $k_{b}=15, \eta_{b}=15$ and $k_{b}=\infty$, $\eta_{b}=\infty$. The amplitude of reflected wave signal for the case 


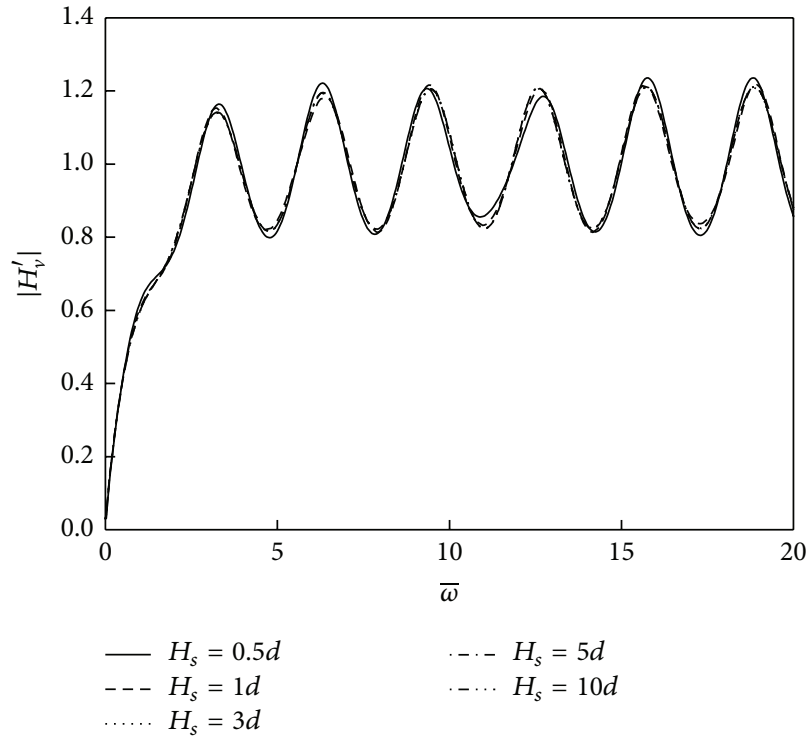

(a) Velocity admittance curves

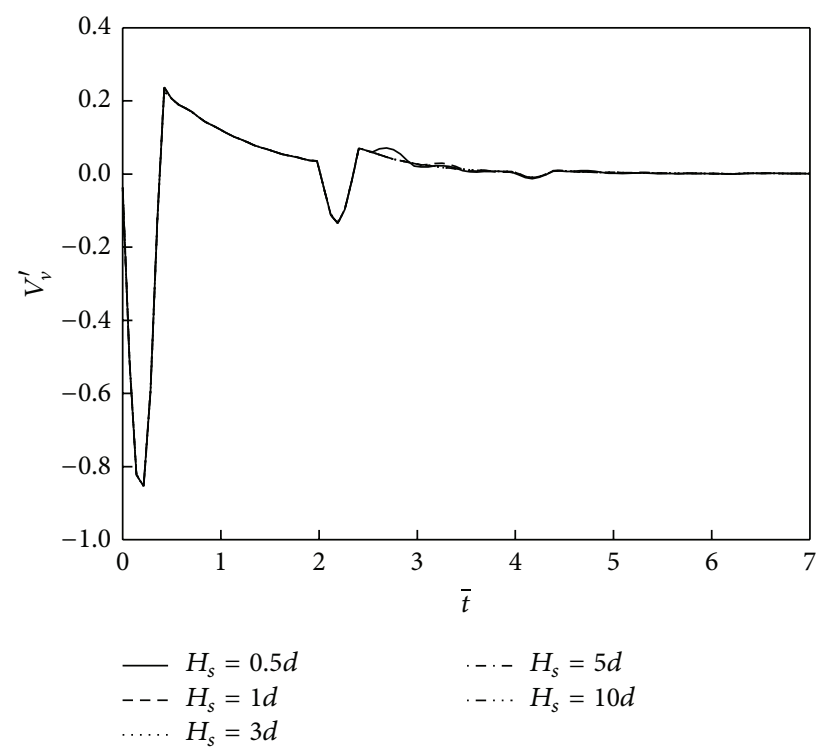

(b) Reflected wave signal curves

FIGURE 6: Influence of thickness of pile end soil on the dynamic response at pile head when $V_{p, 2}=3600 \mathrm{~m} / \mathrm{s}$.

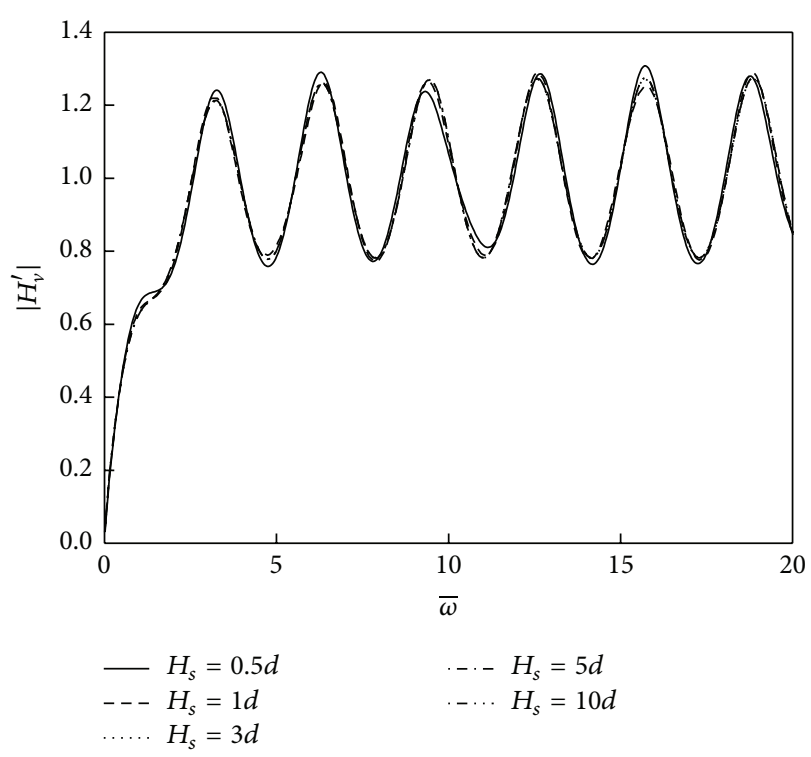

(a) Velocity admittance curves

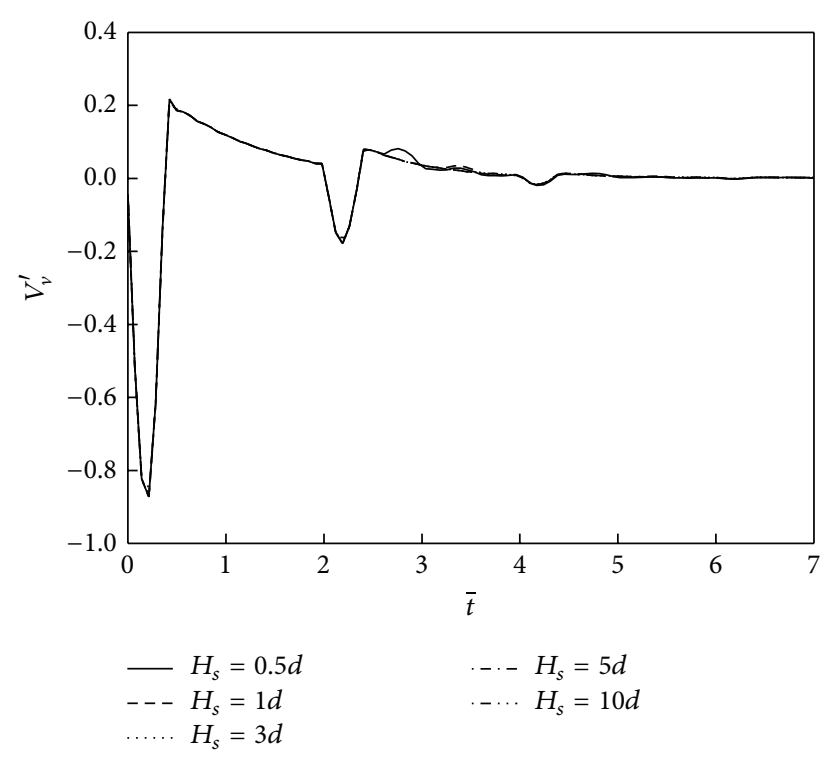

(b) Reflected wave signal curves

FIGURE 7: Influence of thickness of pile end soil on the dynamic response at pile head when $V_{p, 2}=4000 \mathrm{~m} / \mathrm{s}$.

of fictitious soil-pile model is between that of free support and rigid support. As can be seen from the results of the analysis, it is shown that the fictitious soil-pile model is reliable and can be simulated in other support models by varying parameters of pile end soil.

\section{Conclusions}

(1) By introducing the fictitious soil-pile model, this paper derived the analytical solution of velocity response at pile head in frequency domain and its corresponding semianalytical solution of velocity response at pile head in time domain. Whereafter, the influence of parameters of pile end soil on the dynamic response at pile head is investigated in detail.

(2) The finite pile end soil layer adjacent to the pile end has significant influence on the dynamic response at pile head, and there is a critical influence thickness for pile end soil. If the thickness of pile end soil is within the critical influence thickness, the increase of the thickness of pile end soil can dramatically affect the dynamic response at pile head. If 


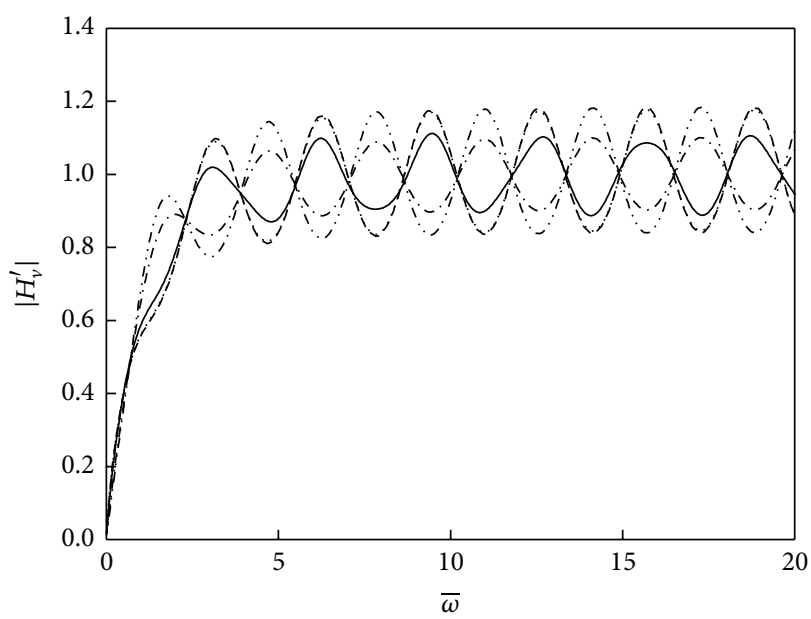

$$
\begin{aligned}
& \text { - Fictitious soil-pile model } \ldots-k_{b}=15, \eta_{b}=15 \\
& \text { - - } k_{b}=0, \eta_{b}=0 \quad-\cdots k_{b}=\infty, \eta_{b}=\infty \\
& \text { …... } k_{b}=0.1, \eta_{b}=0.06
\end{aligned}
$$

(a) Velocity admittance curves

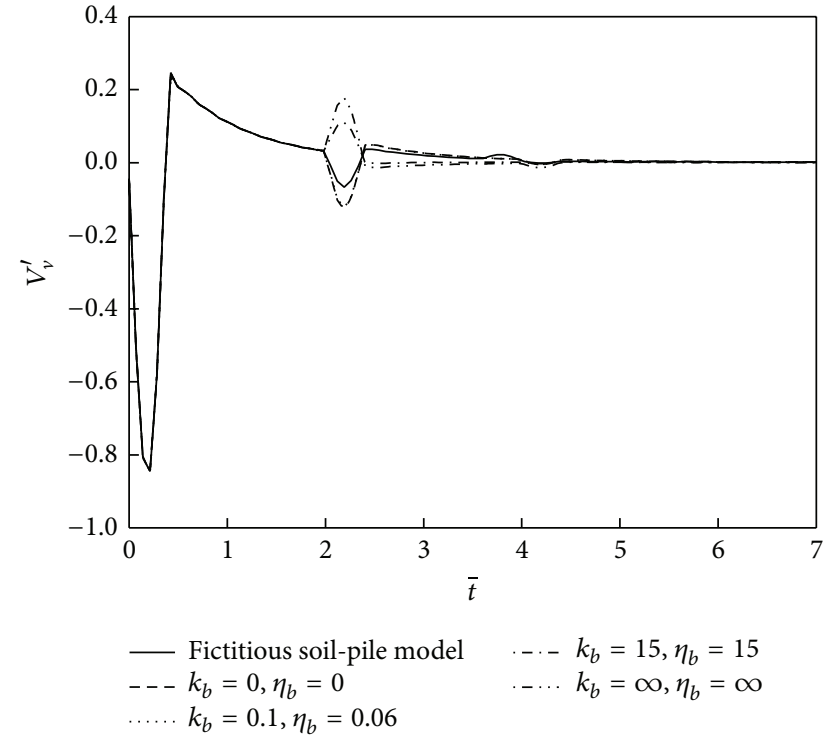

(b) Reflected wave signal curves

FIGURE 8: Comparison of the fictitious soil-pile model with other support models.

the thickness of pile end soil is beyond the critical influence thickness, the further increase of the thickness of pile end soil has little influence on the dynamic response at pile head.

(3) The influence of parameters of pile end soil on the dynamic response at pile head may be more remarkable with the decrease of pile length and with the increase of pile radius and elastic longitudinal wave velocity of pile.

\section{Conflict of Interests}

The authors declare that there is no conflict of interests regarding the publication of this paper.

\section{Acknowledgments}

This research is supported by the National Natural Science Foundation of China (Grant nos. 51309207 and 51378514), the China Postdoctoral Science Foundation Funded Project (Grant nos. 2012M521495 and 2013T60759), and the Fundamental Research Funds for the Central Universities (Grant no. CUG120821).

\section{References}

[1] M. Novak and Y. O. Beredugo, "Vertical vibration of embedded footings," Journal of the Soil Mechanics and Foundations Division ASCE, vol. 98, no. SM12, pp. 1291-1131, 1972.

[2] T. Nogami and K. Konagai, "Time domain axial response of dynamically loaded single piles," Journal of Engineering Mechanics ASCE, vol. 112, no. 11, pp. 1241-1252, 1986.

[3] K. H. Wang, K. H. Xie, and G. X. Zeng, "Analytical solution to vibration of finite length pile under exciting force and its application," Chinese Journal of Geotechnical Engineering, vol. 19, no. 6, pp. 27-35, 1997 (Chinese).
[4] D. S. Kong, M. T. Luan, and Q. Yang, "Review of dynamic Winkler model applied in pile-soil interaction analyses," World Information on Earthquake Engineering, vol. 21, no. 1, pp. 12-17, 2005 (Chinese).

[5] D. J. Liu, "Longitudinal waves in piles with exponentially varying cross sections," Chinese Journal of Geotechnical Engineering, vol. 30, no. 7, pp. 1066-1071, 2008 (Chinese).

[6] K. H. Wang, W. B. Wu, Z. Q. Zhang, and C. J. Leo, "Vertical dynamic response of an inhomogeneous viscoelastic pile," Computers and Geotechnics, vol. 37, no. 4, pp. 536-544, 2010.

[7] T. Nogami and M. Novak, "Soil-pile interaction in vertical vibration," Earthquake Engineering and Structural Dynamics, vol. 4, no. 3, pp. 277-293, 1976.

[8] A. S. Veletsos and K. W. Dotson, "Vertical and torsional vibration of foundations in inhomogeneous media," Journal of Geotechnical Engineering Division ASCE, vol. 114, no. 9, pp. 1002-1021, 1988.

[9] G. Militano and R. K. N. D. Rajapakse, "Dynamic response of a pile in a multi-layered soil to transient torsional and axial loading," Geotechnique, vol. 49, no. 1, pp. 91-109, 1999.

[10] H. D. Wang and S. P. Shang, "Research on vertical dynamic response of single-pile in radially inhomogeneous soil during the passage of Rayleigh waves," Journal of Vibration Engineering, vol. 19, no. 2, pp. 258-264, 2006 (Chinese).

[11] K. H. Wang, D. Y. Yang, and Z. Q. Zhang, "Study on dynamic response of pile based on complex stiffness transfer model of radial multizone plane strain," Chinese Journal of Rock Mechanics and Engineering, vol. 27, no. 4, pp. 825-831, 2008 (Chinese).

[12] R. K. N. D. Rajapakse, Y. Chen, and T. Senjuntichai, "Electroelastic field of a piezoelectric annular finite cylinder," International Journal of Solids and Structures, vol. 42, no. 11-12, pp. 3487-3508, 2005.

[13] T. Senjuntichai, S. Mani, and R. K. N. D. Rajapakse, "Vertical vibration of an embedded rigid foundation in a poroelastic soil," 
Soil Dynamics and Earthquake Engineering, vol. 26, no. 6-7, pp. 626-636, 2006.

[14] K. H. Wang, Z. Q. Zhang, C. J. Leo, and K. H. Xie, "Dynamic torsional response of an end bearing pile in transversely isotropic saturated soil," Journal of Sound and Vibration, vol. 327, no. 3-5, pp. 440-453, 2009.

[15] C. B. Hu and X. M. Huang, "A quasi-analytical solution to soil-pile interaction in longitudinal vibration in layered soils considering vertical wave effect on soils," Journal of Earthquake Engineering and Engineering Vibration, vol. 26, no. 4, pp. 205211, 2006 (Chinese).

[16] L. C. Liu, Q. F. Yan, and X. Yang, "Vertical vibration of single pile in soil described by fractional derivative viscoelastic model," Engineering Mechanics, vol. 28, no. 8, pp. 177-182, 2011 (Chinese).

[17] J. Lysmer and F. E. Richart, "Dynamic response of footing to vertical load," Journal of the Soil Mechanics and Foundations Division ASCE, vol. 2, no. 1, pp. 65-91, 1966.

[18] R. Y. Liang and A. I. Husein, "Simplified dynamic method for pile-driving control," Journal of Geotechnical and Geoenvironmental Engineering ASCE, vol. 119, no. 4, pp. 694-713, 1993.

[19] G. G. Meyerhof, "Bearing capacity and settlement of pile foundations," Journal of Geotechnical Engineering Division ASCE, vol. 102, no. GT3, pp. 195-228, 1976.

[20] D. Y. Yang and K. H. Wang, "Vertical vibration of pile based on fictitious soil-pile model in inhomogeneous soil," Journal of Zhejiang University (Engineering Science), vol. 44, no. 10, pp. 2021-2028, 2010 (Chinese).

[21] W. B. Wu, K. H. Wang, D. Y. Yang, S. J. Ma, and B. N. $\mathrm{Ma}$, "Longitudinal dynamic response to the pile embedded in layered soil based on fictitious soil pile model," China Journal of Highway and Transport, vol. 25, no. 2, pp. 72-80, 2012 (Chinese).

[22] W. B. Wu, K. H. Wang, Z. Q. Zhang, and J. Z. Chen, "Accuracy and application of virtual soil pile model in half space foundation," Journal of Basic Science and Engineering, vol. 20, no. 1, pp. 121-129, 2012 (Chinese). 


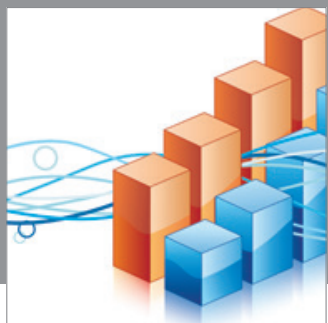

Advances in

Operations Research

mansans

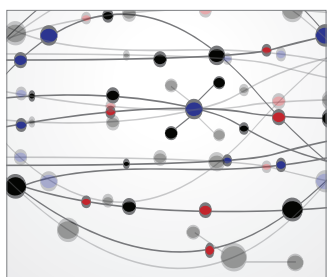

The Scientific World Journal
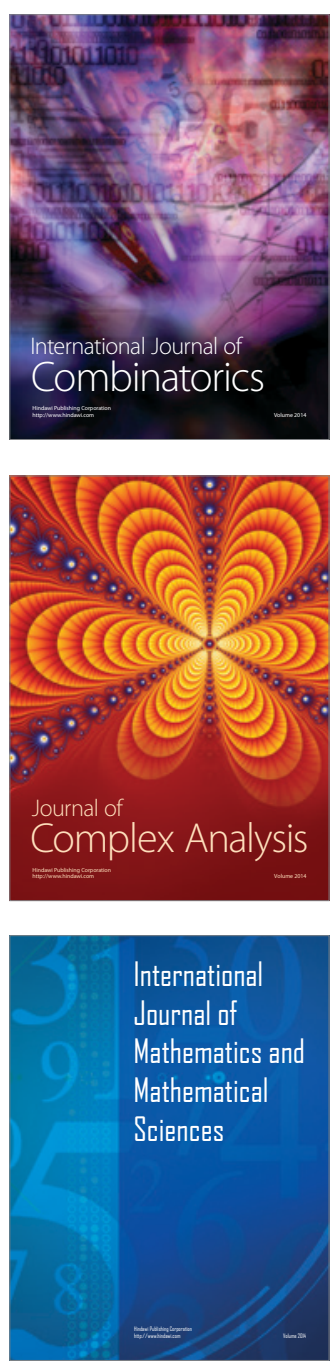
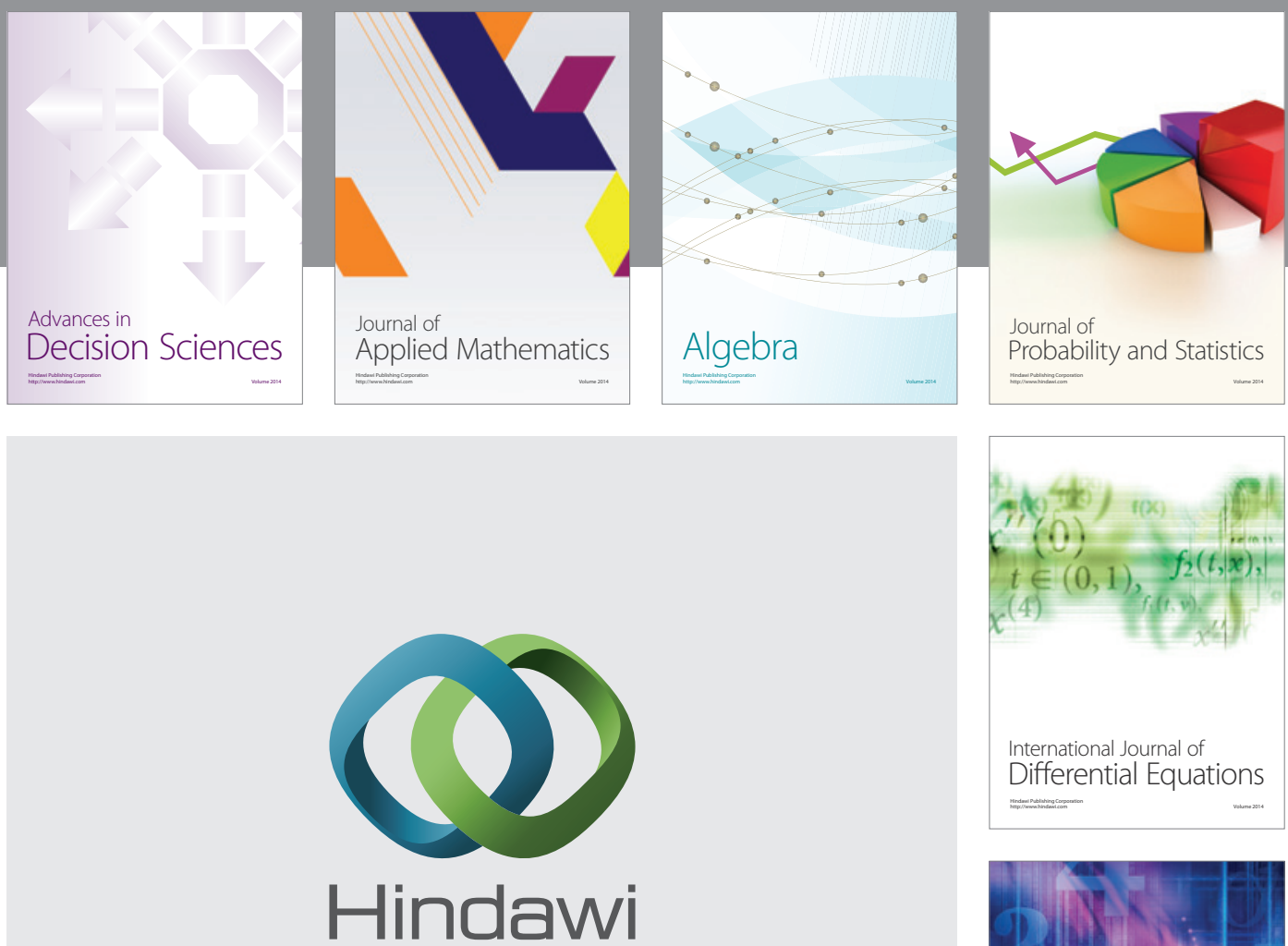

Submit your manuscripts at http://www.hindawi.com
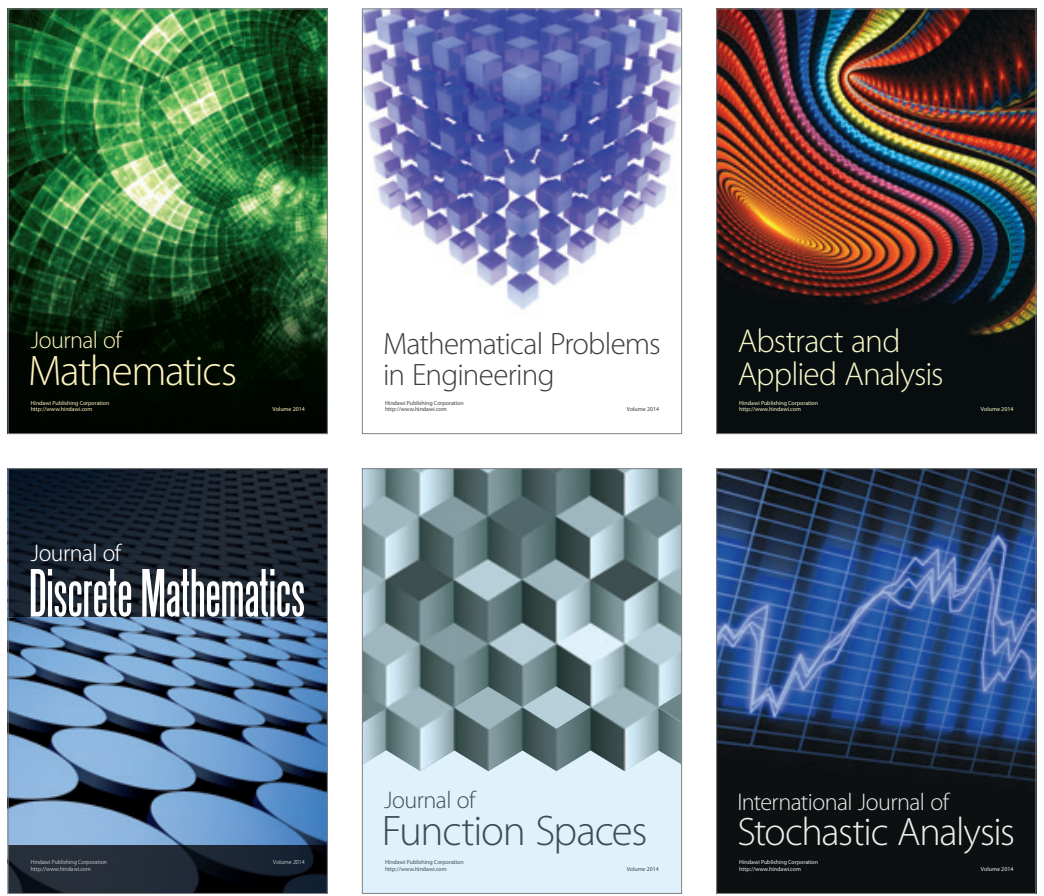

Journal of

Function Spaces

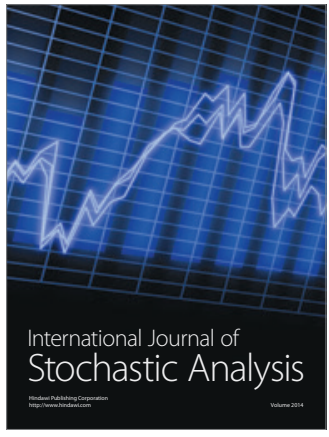

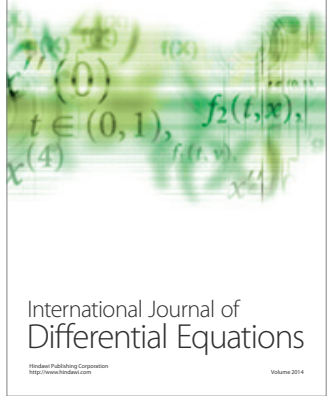
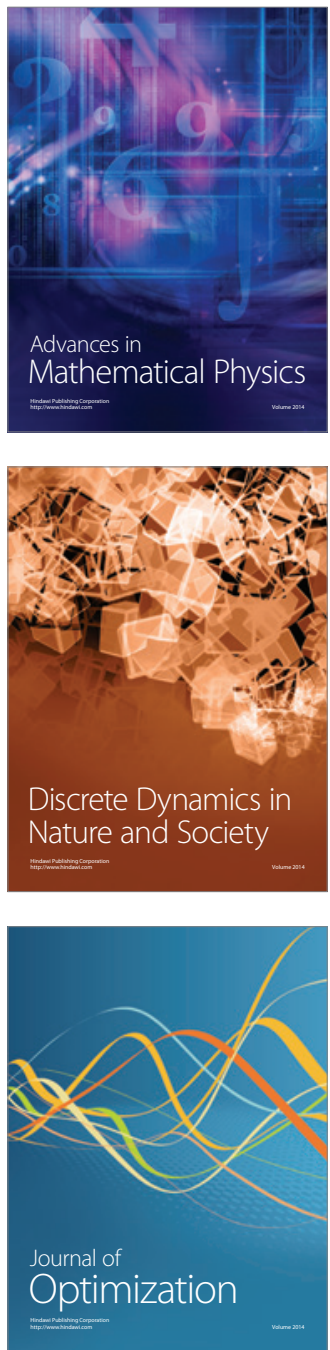